GEOLOGICA BALCANICA 50 (3), Sofia, December 2021, pp. 55-63.

\title{
Assessment of the factors affecting slope stability in the southern part of the Sofia Kettle
}

\author{
Miroslav Krastanov, Boyko Berov \\ Geological Institute, Bulgarian Academy of Sciences, Acad. G. Bonchev Str., Bl. 24, 1113 Sofia, Bulgaria; \\ e-mails:miro_k@geology.bas.bg; b_berov@geology.bas.bg
}

(Received: 12 November 2021; accepted in revised form: 10 December 2021)

\begin{abstract}
A specific sample area was selected, where an assessment model was made for the stability of a slope subjected to anthropogenic impacts. A hillside slope zone from the foot of the Vitosha and Lozen mountains in the southern periphery of the Sofia Kettle was chosen as an exemplary area for a part of the hazards arising in the Trans-Balkan valleys. The anthropogenic impact on their slope stability was studied on three particular slopes. The study area is about $1.25 \mathrm{~km}^{2}$ and has a maximum distance of up to $3.80 \mathrm{~km}$ between the slopes. Landslide processes resulting from anthropogenic impact often occur on the territory of the Sofia Valley. The rise of construction, the development of hard-to-reach terrains with steep slopes, their undercutting, the seismic impact and the low values of the strength-deformation parameters of the geological varieties building up the respective terrains contribute to their occurrence. The deforestation, the loads with heavy embankments, the hydration and the inhomogeneity of the layers of the earth base have a strong destabilizing effect. The paper presents the results of field and laboratory tests and analyses of slope stability by the method of Fellenius. The severity of the impact of the various destabilizing factors was assessed.
\end{abstract}

Krastanov, M., Berov, B. 2021. Assessment of the factors affecting slope stability in the southern part of the Sofia Kettle. Geologica Balcanica 50 (3), 55-63.

Keywords: landslide, slope stability, factor of safety, Sofia Kettle.

\section{INTRODUCTION}

The size of the anthropogenic impact in Bulgaria is constantly growing and is approaching that of the naturally occurring processes. The similarity between them is due to their identical physical nature. There are also differences between them, the most significant of which is that anthropogenic processes are subject to human control. This includes the possibility of reducing the negative impact of human activity on the stability of the slopes.

The main types of anthropogenic impact on the slopes, changing their stability, are the digging works carried out during the construction of excavations, construction of irrigation canals and water supply installations, construction of road and railway infrastructures, deforestation of slopes and embankment cumulation (e.g., Frangov, 1990; Berov, 2002; Yaneva et al., 2002; Krastanov, 2020). In combination with these technogenic influences, the seismic activity of the region and the geological and tectonic conditions lead to sudden hazardous consequences and great damages.

From the geological and tectonic conditions, important for the stability of the slopes are the elements of the layers, the thickness and distribution of different lithological layers, the presence of clay soils in the geological section and their location, the presence or absence of weak contacts, presence of groundwater, interbeds and interlayer surfaces, fault zones. 
The Sofia Kettle has been described as one of the regions in the country where landslides often occur due to anthropogenic impact (Bruchev et al., 2006; Berov, 2008). The consequences are often associated with significant material damage, e.g., cracking and destruction of buildings and facilities, disruption of transport infrastructure and, sometimes, human casualties. This article examines three areas for assessment of the anthropogenic impact on the slopes located in the southern part of the Sofia Kettle (Fig. 1).

\section{METHODOLOGY}

Field and laboratory tests were performed for the study of the selected three areas. The tests were carried out in accordance with European standards (EN). A minimum of three exploratory drillings were made for each profile to establish the geological structure and the spatial position of the strata.

Shear strength parameters were obtained by the laboratory direct shear test on undisturbed soil samples and from heavy-type penetrometer (DPH) penetration test.

The Fellenius method was used to determine slope stability. With this method (only valid for circular slide surfaces), internal forces between sepa- rate slices are ignored and, thereby, the unknowns were reduced to: $n$ values of normal forces $\mathrm{Ni}$; $n$ values of shear forces Ti; and factor of safety Fs (Fellenius, 1927).

The slope analyses were performed with the program SLOPE of the Italian company GEOSTRU Ltd. This slope stability software carries out the analysis of soil or rock slope stability under both static and seismic conditions, using the limit equilibrium methods of Fellenius, Bishop, Janbu, Bell, Sarma, Spencer, Morgenstern and Price and DEM (https://www.geostru.eu/?lang=en).

The following features of the program were used in the present study: 1) recalculate function to evaluate the safety factor of a specific surface with center $\mathrm{X}_{0}, \mathrm{Y}_{0}$ and radius $\mathrm{R}$; 2) identification of the critical slide surface though automatic calculation; 3) automatic computation of safety factor for surfaces that are tangential to a straight line vector; and 4) presence of seismicity and aquifers.

\section{GEOLOGICAL, GEOMORPHOLOGICAL AND ENGINEERING GEOLOGICAL CONDITIONS}

The Sofia Kettle represents a complex asymmetric graben of block structure at a depth of up to $1100 \mathrm{~m}$, filled with thick Neogene and Quaternary deposits.

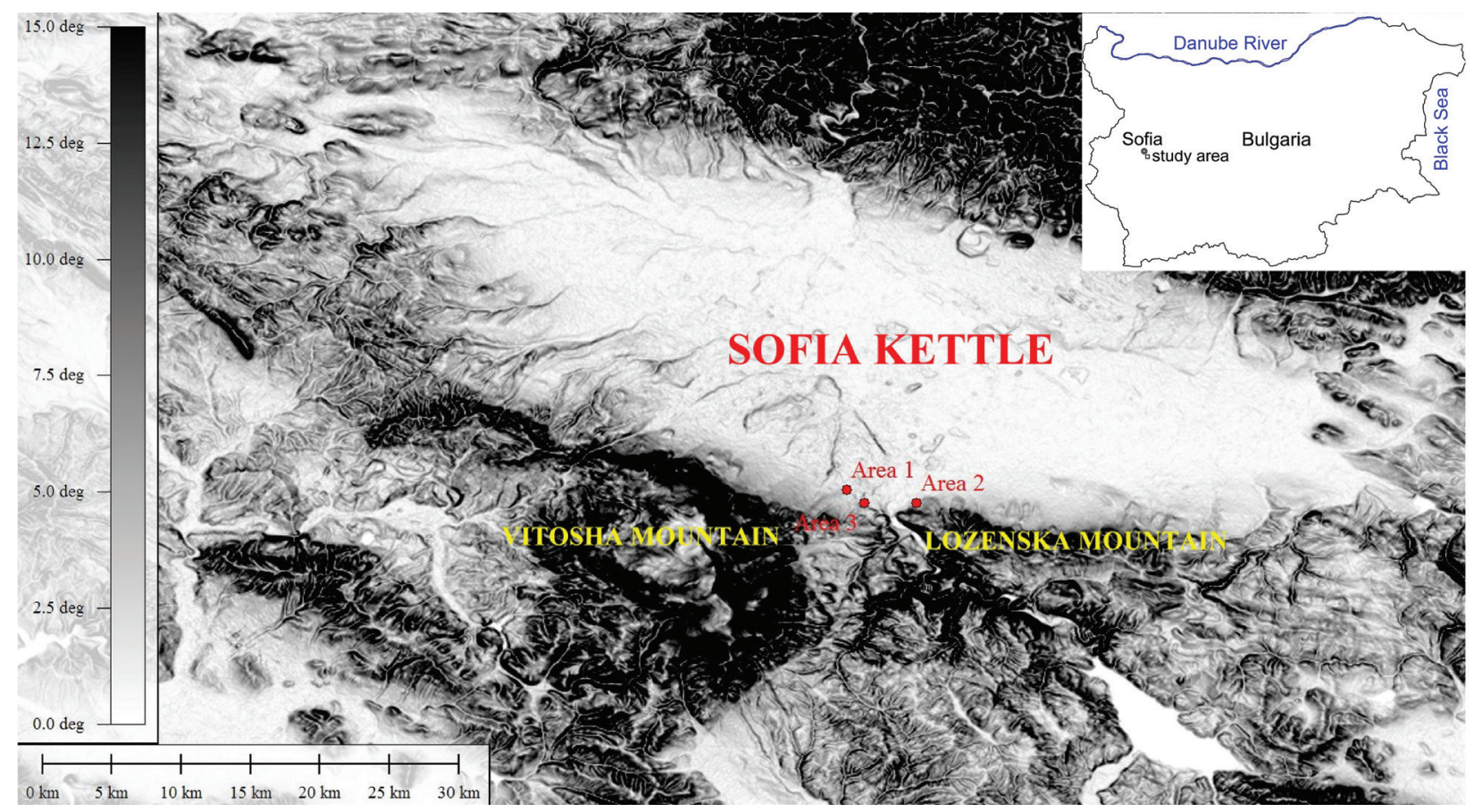

Fig. 1. Slope map (in degrees) and location of the studied areas (QGIS - slope analysis). 
The graben belongs to the West Srednogorie structural region. It is separated by a complex fault system from the surrounding mountains: the Sofia Mountain to the north, the Lozen and Vitosha mountains to the south, the Lyulin Mountain and the Slivnitsa hills to the west, and the western parts of the Ihtimanska Sredna Gora Mountain to the east. The boundaries are determined by the distribution of the Neogene and Quaternary deposits in the places where they come into contact with the older formations.

The Sofia Kettle is filled with upper Neogene lake sediments represented by loose and more or less compacted sediments, mainly sandy and silty clays, clays, sands, lignite coals, gravels, conglomerates (Yaneva et al., 2002). The uppermost part of the Neogene sediments is represented by the Lozenets Formation. These deposits are the soil base for construction purposes on the territory of Sofia City and the greater part of the kettle itself. They are represented, to a depth of 25-30 m, by sands of various grain size (silty, fine, small- and mediumsized sands), as well as silty to silty-sandy clays. The gravels among them are in the form of lenses or intercalations with clayey-sandy filler. The great variety in the lithological composition of these deposits determines the diversity and the variation of their physical and mechanical properties in a broad range. An important feature of the granulometry of the clays is their high silt content (42-82\%), which explains to a great degree the peculiarities in their physical and mechanical properties, such as low bulk density, high pore coefficient, high moisture content and plastic consistency (Bozhinova and Ilieva, 1990; Ivanov, 2001; Bozhinova-Haapanen and Uusinoka, 2014; Stoynev and Lakov, 2017; Svalova et al., 2020). The decrease in the physical and mechanical parameters is almost parallel with the increase in the silt fraction.

The Neogene deposits are covered by Quaternary sediments of irregular thickness, represented by a culture layer, brown and black silty clays, alluvial gravel and sands building the river terraces, and deluvial and alluvial fan boulders, gravels and silty and sandy clays along the peripheral parts of the kettle. A characteristic feature of the sediments filling the kettle is their frequent facial variability, inconsistency of composition, thickness and properties in both vertical and horizontal direction. In general, the Quaternary soils possess relatively high pore volume and low deformation module. That is the reason for the differences in their distribution, composition and properties, reflecting on the construction conditions and on the manifestation of various unfavorable engineering geological processes and phenomena (Ivanov and Angelova, 1997; Ivanov et al., 1998; Yaneva and Donkova, 2017).

The genesis of the lithological varieties largely determines their properties and accounts for the origin and development of the different processes. The geodynamic processes and phenomena observed in the kettle are diverse, e.g., landslides, dry shrinkage of clays, swelling of clays, marshlands, suffusion, sand liquefaction, seismicity (Frangov and Dobrev, 1991; Konstantinov et al., 1992; Iliev-Broutchev, 1994; Berov and Ivanov, 1995; Ivanov, 1996, 1997, 2002; Berov and Frangov, 1997; Ivanov and Frangov, 2000). The Sofia Valley is a seismically active zone with several strong manifestations of earthquake during the last two centuries.

The study area is characterized by a complex geological structure (Antonov et al., 2011). The studied terrain is represented by materials of proluvial and deluvial origin. Proluvial deposits cover the Neogene sediments or older rocks with an uneven, unclear boundary. They are represented by blockboulder unsorted conglomerates, quartz sandstones and andesites.

The deluvial deposits fill the inter-cone depressions at the northern foot of the Vitosha and Lozen mountains. They are built up of coarse-grained deposits with a clayey or clayey-sandy matrix with ridged pieces up to $2-3 \mathrm{~cm}$, mostly of quartz. The pieces are gravel and boulder in size. In some places, there is a rough layering, emphasized by thin clay layers and the arrangement of small rock fragments. From an engineering geological point of view, the studied area is a part of the foot of the Vitosha and Lozen mountains and is characterized by the manifestation of the so-called slow creep on the slopes. In case of unplanned technogenic intervention in such slope sections, the manifestation of active landslide processes with unpredictable consequences is possible.

Geomorphologically, the region is the northern periphery of the proluvial deposits at the foot of the Vitosha and Lozenska mountains.

The altitude of study area 1 (the southern arc of the ring road of Sofia) is in the range from 633 $\mathrm{m}$ to $642 \mathrm{~m}$. For study area 2 (German Village), it is in the range of 590-599 $\mathrm{m}$ and, for study area 3 (residential district Pancharevo of Sofia City), it is in the range of 623-642 $\mathrm{m}$. The terrain morphology is additionally modeled by anthropogenic impact (embankments and excavations).

The spatial locations and cross-sections of the established geological layers in the studied areas are illustrated in Figs 2-4. 


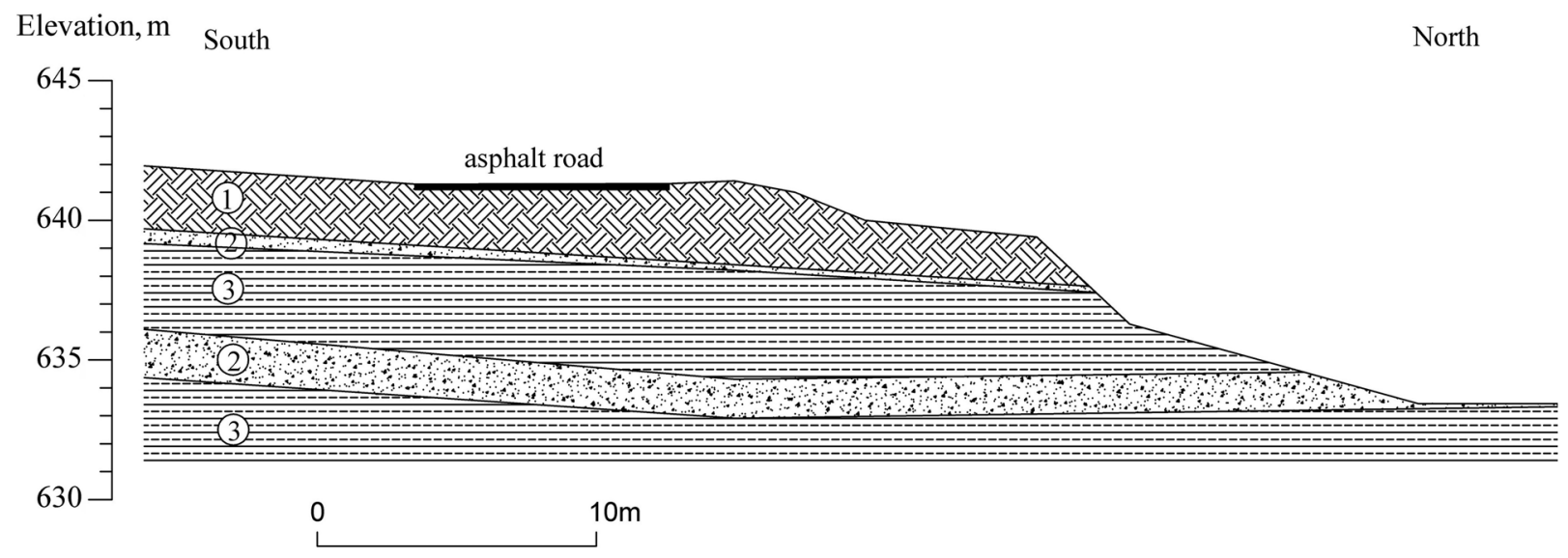

Fig. 2. Geological cross-section of study area 1: 1 - Embankment: sandy clay to clay, sand and gravel with construction waste tQh; 2 - Fine-grained sand with gravel $\mathrm{lN}_{2} ; 3$ - Silty-sandy clay $\mathrm{lN}_{2}$.

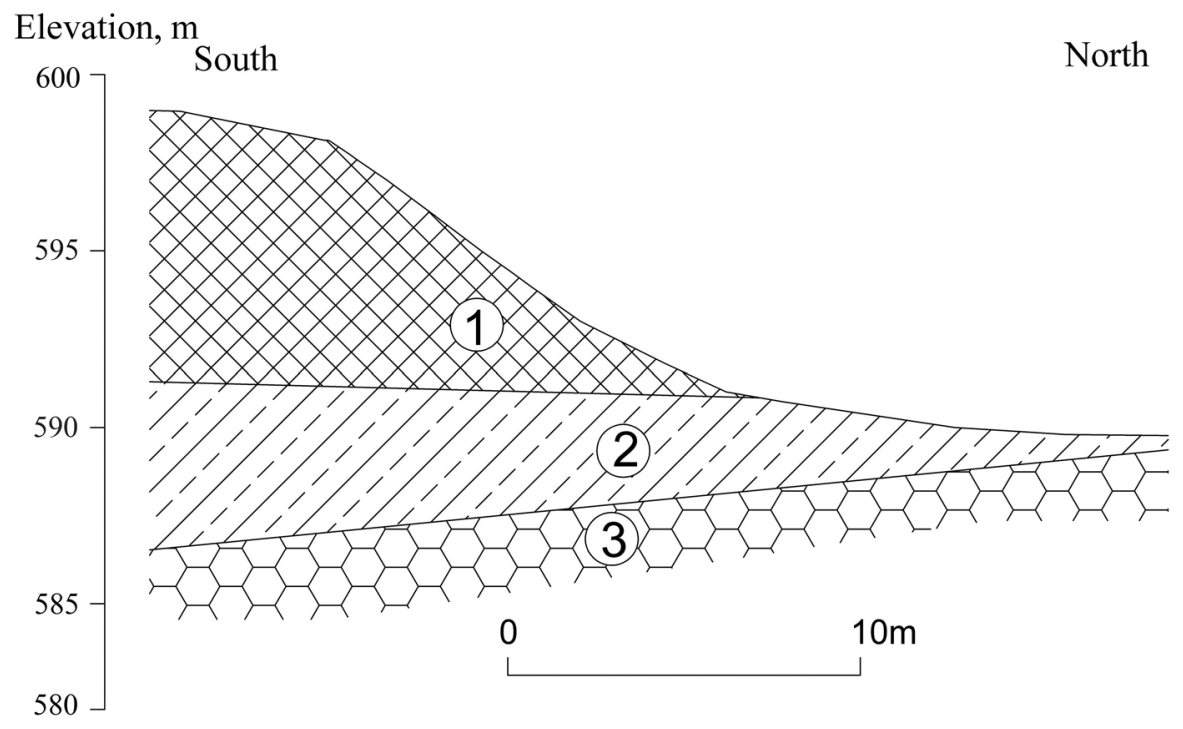

Fig. 3. Geological cross-section of study area 2: 1 - Embankment: silty clays to silty sandy clays with gravels tQh; 2 - Clays to sandy clays pr-dQh; 3 - Block-boulder conglomerates, quartz sandstones and andesites $\operatorname{prN}_{2}-\mathrm{Qp}$.

\section{GEOTECHNICAL CONDITIONS AND SLOPE STABILITY}

The presence of sustained inclined clay layers with a tendency to creep at a small part of the tangential stress is of crucial importance for the stability of many slopes.

Depending on the genesis, lithological features and physical and mechanical parameters of the varieties in study area 1 , three engineering geological layers were distinguished. Three engineering geological strata were also identified in study area 2; only two geological strata were identified in area 3.

Shear strength parameters, which were used to estimate the safety factor, were obtained by laboratory plane shear tests on undisturbed soil samples and by heavy-type penetrometer (DPH) penetration test (Table 1).

When compiling the computational geomechanical model, the results of the engineering geologi- 


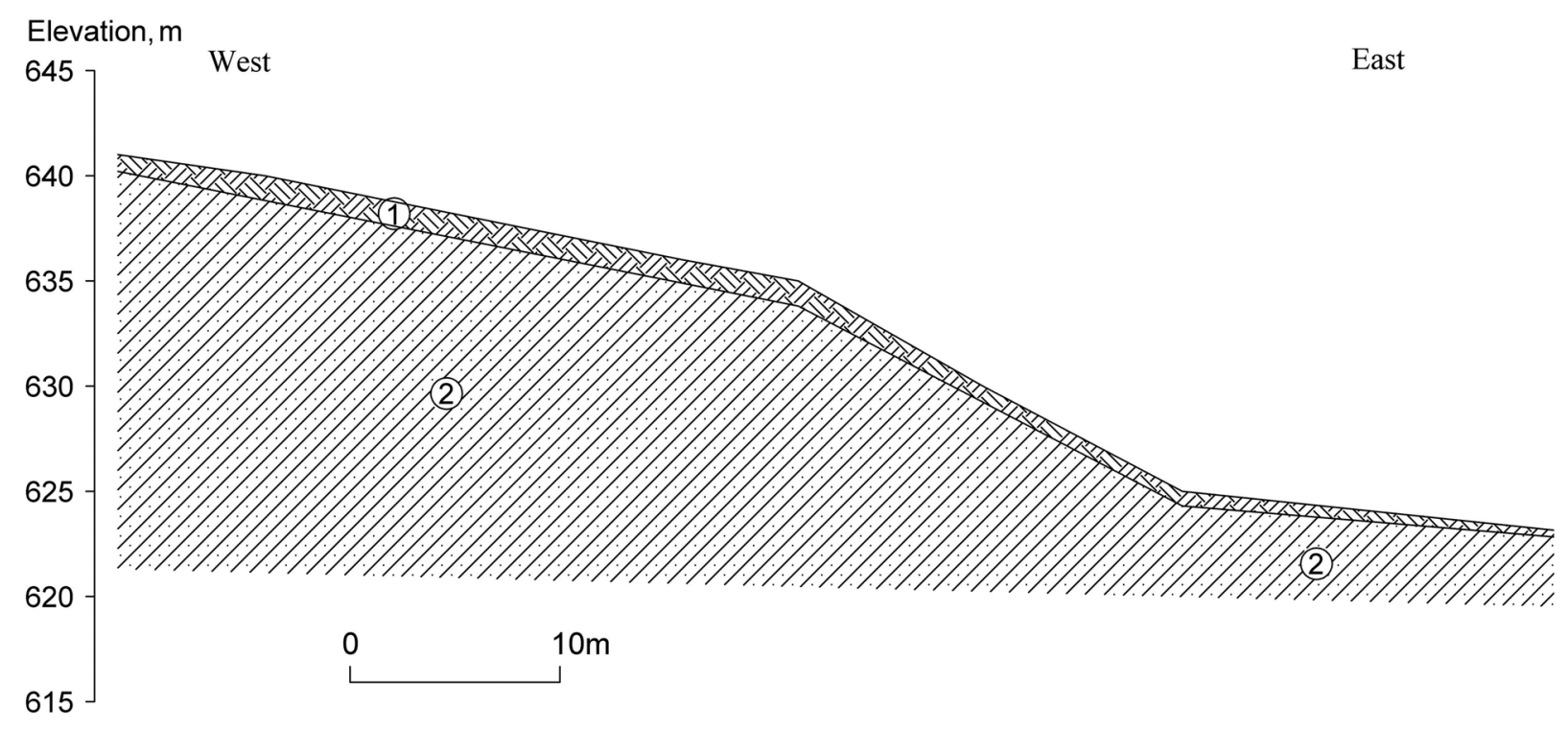

Fig. 4. Geological cross-section of study area 3: 1 - Silty clays Qh; 2 - Sandy clay to clay with gravel and boulders pr-dQp.

Table 1

Values of physical and mechanical parameters of different layers in the studied areas

\begin{tabular}{|c|c|c|c|}
\hline Geological strata & $\begin{array}{l}\text { Bulk } \\
\text { weight } \\
\gamma \\
\mathrm{kN} / \mathrm{m}^{3}\end{array}$ & $\begin{array}{c}\text { Angle of internal } \\
\text { friction, } \varphi \\
\text { deg. }\end{array}$ & $\begin{array}{c}\text { Cohesion, } \\
\text { c } \\
\mathrm{kN} / \mathrm{m}^{2}\end{array}$ \\
\hline \multicolumn{4}{|c|}{ study area 1} \\
\hline Layer 1 & 18.9/(18.0-19.4) & 13.0/(12.1-14.3) & $28.0 /(26.3-29.2)$ \\
\hline Layer 2 & 18.8/(16.4-20.0) & $34.0 /(29.0-38.0)$ & $2.0 /(1.3-2.5)$ \\
\hline Layer 3 & 19.2/(18.9-19.6) & 24.0/(22.2-25.8) & $35.0 /(32.1-38.2)$ \\
\hline \multicolumn{4}{|c|}{ study area 2} \\
\hline Layer 1 & 18.7/(17.9-19.9) & 12.9/(12.1-22.8) & $31.0 /(26.3-59.0)$ \\
\hline Layer 2 & 19.3/(18.3-20.5) & 14.1/(8.1-21.4) & $26.0 /(28.3-92.5)$ \\
\hline Layer 3 & $26.0 /(26.0-26.1)$ & $31.0 /(-)$ & $59.6 /(-)$ \\
\hline \multicolumn{4}{|c|}{ study area 3} \\
\hline Layer 1 & 17.0/(18.0-19.4) & 14.0/(13.4-15.2) & 7.0/(5.8-8.9) \\
\hline Layer 2 & 19.9/(18.0-21.0) & $9.4 /(7.5-11.8)$ & $50.5 /(10.0-148.0)$ \\
\hline
\end{tabular}

Note: numerator - average value (samples); denominator - min-max.

cal studies, the geomorphological features of the slope and the physical and mechanical indicators of the construction soils were taken into account. The slope analyses were performed on 168 to 449 sliding surfaces. The following variants were studied: stability of a slope in its natural state at a basic combination of loads, at a water-saturated slope, at a loaded slope and an earthquake of IX degree ac- cording to MSK-64 and seismic coefficient 0.27. The results of the stability analyses are shown in Figs 5-7. These figures show the contours of the sliding surfaces, on which the safety factors Fs for the different states were calculated, the number of lamellae and the network with the centers of equilibrium. The values obtained for the coefficient of stability are given in Table 2. 


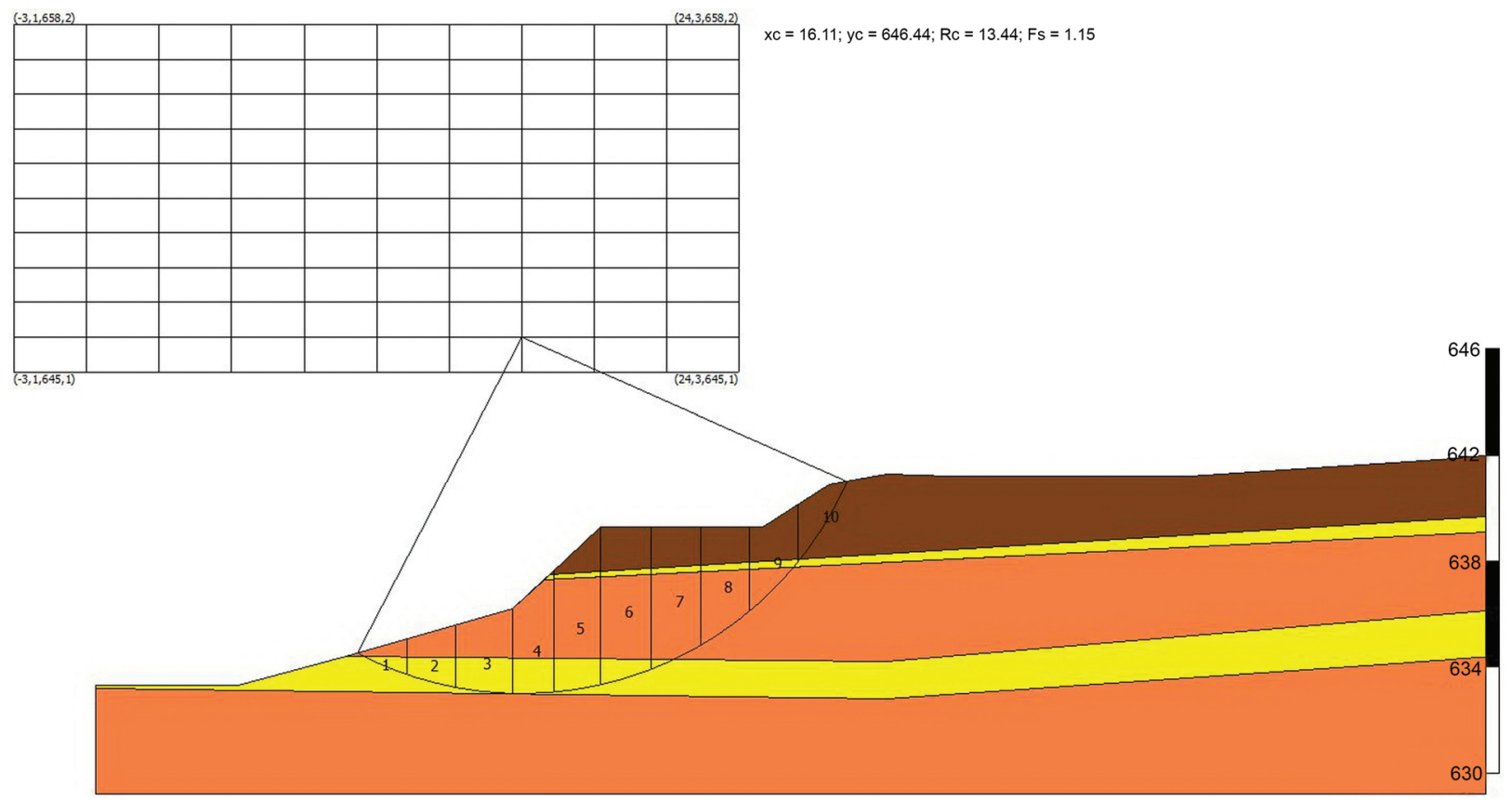

Fig. 5. Computational cross-section of study area 1 for slope stability.

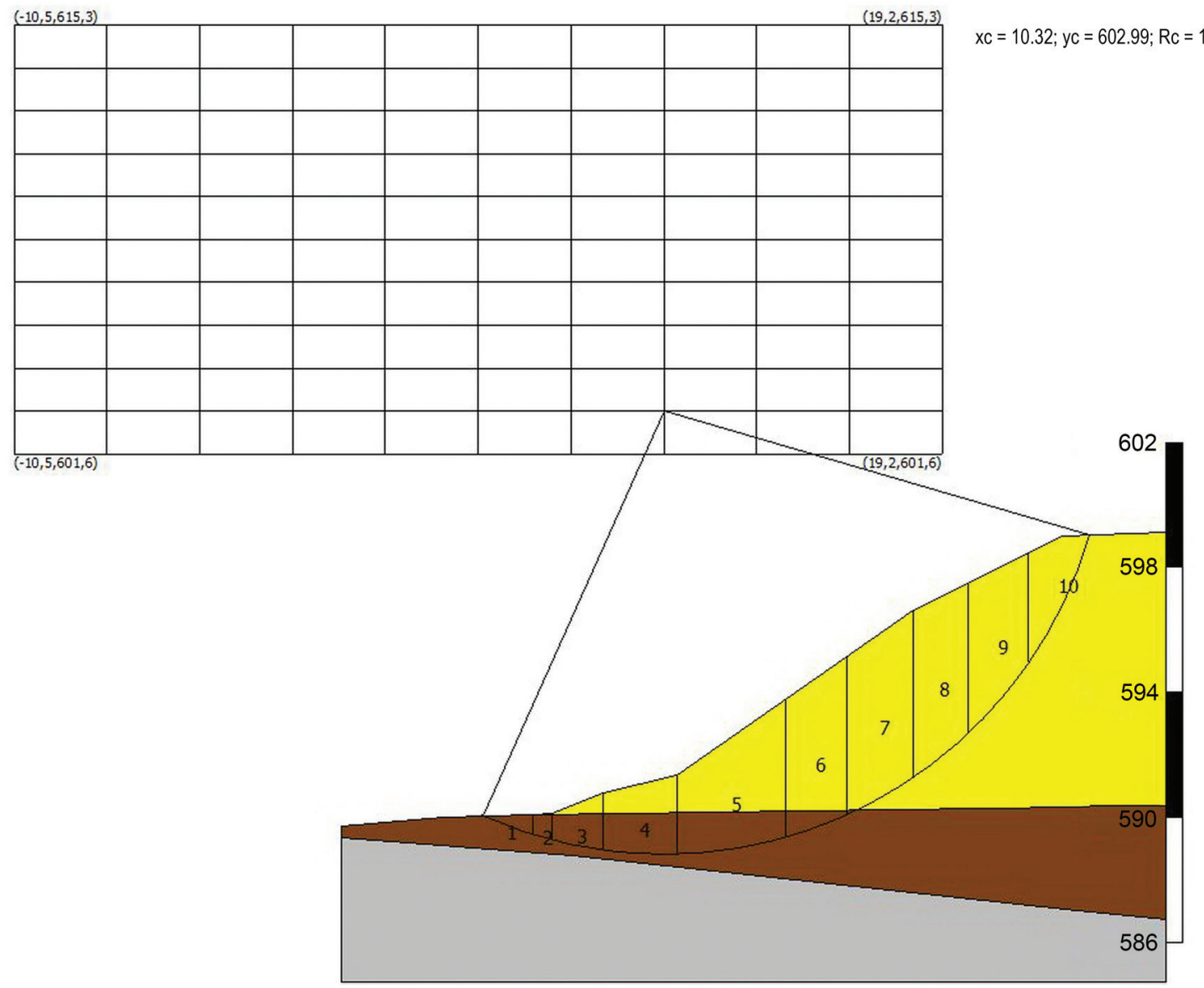

Fig. 6. Computational cross-section of study area 2 for slope stability. 


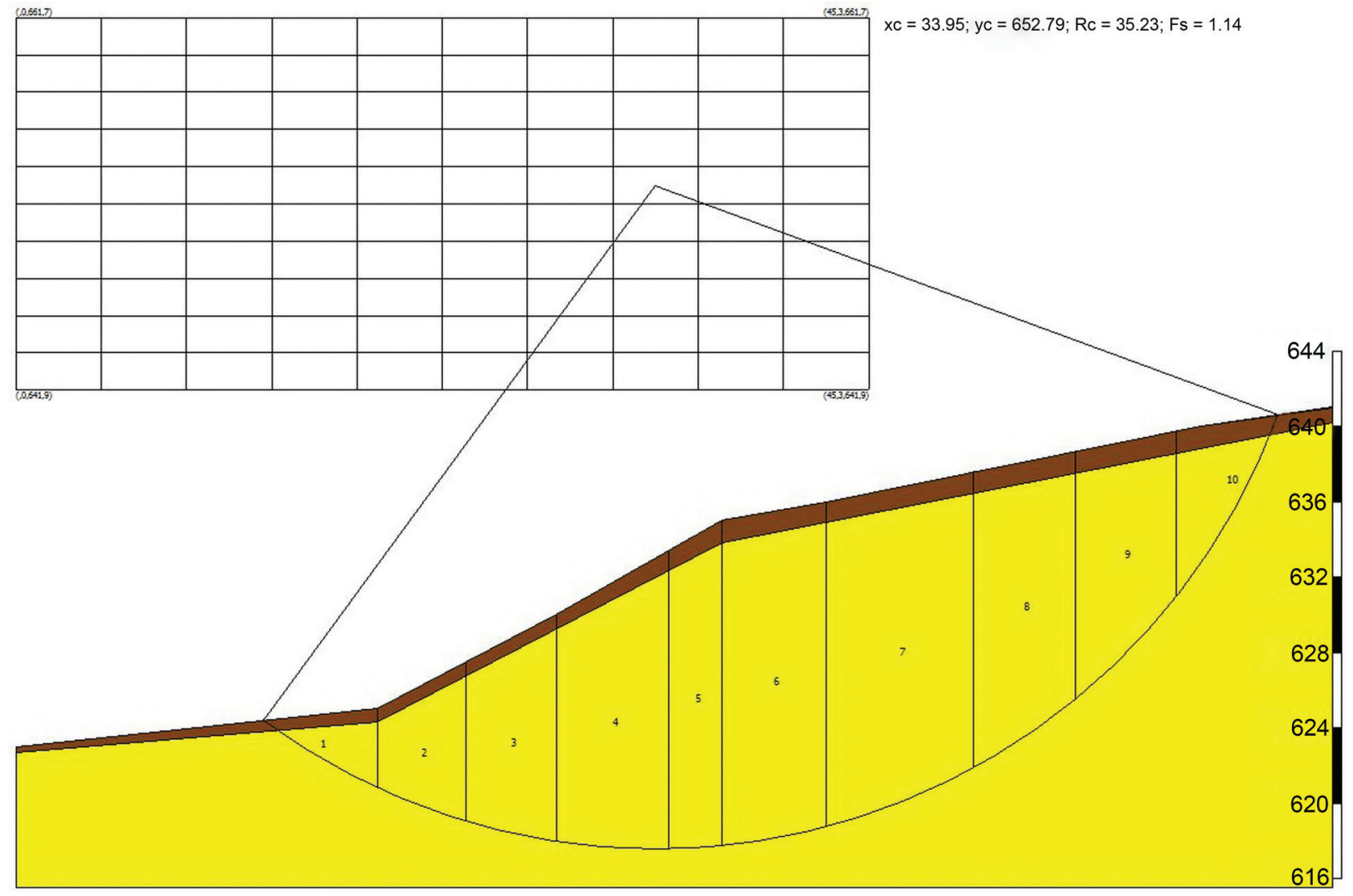

Fig. 7. Computational cross-section of study area 3 for slope stability.

Table 2

Results for slope stability

\begin{tabular}{lcc}
\hline \multicolumn{1}{c}{ Slope condition } & Cross-section & Factor of safety \\
& & $\mathrm{F}_{\mathrm{s}}$ \\
\hline Natural terrain & & 1.15 \\
Water saturated terrain & Area 1 & 1.14 \\
Natural terrain with earthquake & & 0.79 \\
Natural terrain with additional load & & 1.10 \\
\hline Natural terrain & Area 2 & 1.44 \\
Water saturated terrain & & 1.43 \\
Natural terrain with earthquake & & 0.97 \\
Natural terrain with additional load & & 1.26 \\
\hline Natural terrain & & 1.14 \\
Water saturated terrain & Area 3 & 1.13 \\
Natural terrain with earthquake & & 0.75 \\
Natural terrain with additional load & & 1.13 \\
\hline
\end{tabular}

\section{CONCLUSION}

In the selected areas of a slope section at the foot of the Vitosha and Lozen mountains, some peculiarities of the engineering geological conditions in the periphery of the Sofia Valley have been established, which would contribute to the careful assessment when undertaking technogenic intervention in such sections.

From the conducted studies and analyses of the stability of the slopes, the following conclusions can be drawn about the influence of the various factors on the stability of the studied slopes: 
- Technogenic factors have different, mostly negative, influence on the stability of slopes. What they have in common is that the sensitivity of the safety factor to their change depends on the initial state of slope stability, the relative size, the direction and the applied point of impact;

- The used approach allows the technogenic activity to be controlled, managed and forecast so as not to cause landslides;

- It is established that the geological-tectonic, geomorphological, engineering geological and hydrogeological conditions create preconditions for the occurrence of anthropogenic landslides. Important for the formation of the stability of the slopes is the presence of significant amount of clay soils; and stratified sediments with clay layers with an inclination angle unfavorable for slope stability;

- In their natural state, the studied terrains on all three analyzed profiles is in a stable state, as the safety factors are in the range of Fs = 1.13-1.31, depending on the natural slope and the ground varieties;

- The increase in the groundwater level has a weak effect on the stability of the slopes. In the considered cases, the influence of groundwater on the safety factor is assessed as unfavorable, but it reduces the factor of safety by less than 0.01 , which is insignificant;

- With an estimate for maximum earthquake of IX degree according to MSK-64, the stability of the slopes decreases to values of Fs $=0.75$ 0.97 , which characterizes them as unstable.
- When reporting a load at the top of the slope in the amount of a heavy truck, a negative impact is found on the safety factor, which decreases to Fs = 1.10-1.26; nevertheless, the slope remains stable. The negative impact of overload depends on the location of the load. The closer it is to the steep part of the respective slope, the greater its negative impact is;

- Seismic impact has the most adverse effect on the stability of the studied terrains, as the safety factor decreases by $26 \%$ to $34 \%$ of that in the natural state;

- In case of an additional load (building, facility, vehicle or others) of $10-40 \mathrm{kN} / \mathrm{m}^{2}$ on the considered slope, the safety factor decreases by $1-4 \%$;

- The main trigger for the occurrence of landslides may be the seismic impact, as well as a combination of two or more anthropogenic factors. Favorable conditions for the occurrence of anthropogenic landslides occur on slopes with an average inclination of more than $4^{\circ}$.

\section{Acknowledgments}

The present study has been carried out in the Project "National Geoinformation Center (NGIC)" (www. ngic.bg), which is financed by the National Roadmap for Scientific Infrastructure 2017-2023 under Contract No. D01-404/18.12.2020 with the Ministry of Education and Science. The authors wish to thank two anonymous reviewers for their constructive reviews and suggestions, which improved the quality of the manuscript.

\section{REFERENCES}

Antonov, M., Milovanov, P., Popov, A., Bonev, K., Dyulgerov, M., Marinova, R., Sarov, S. 2011. Explanatory notes for the geological map of Bulgaria in scale 1:50 000. Sofia-south map sheet. Ministry of Environment and Water, Bulgarian Geological Survey, Sofia, 51 pp.

Berov, B. 2002. Some anthropogenic changes in the geological environment in Bulgaria. Geologica Balcanica 32 (2-4), 107-111.

Berov, B. 2008. Zoning of Sofia valley according to the level of geological hazard. Geologica Balcanica 37 (1-2), 73-78.

Berov, B., Frangov, G. 1997. Zoning of Sofia valley according to degree of potential landslide hazard. $4^{\text {th }}$ National Scientific and Practical Conference on Scientific Support of Prevention Activities and Protection of the Population in Case of Emergency, 207-215 (in Bulgarian).

Berov, B., Ivanov, P. 1995. Possible secondary seismogenic deformations in Sofia kettle. Proceedings of the $X V$ Congress of the CBGA, 965-969.
Bozhinova, A., Ilieva., L. 1990. Structural and mechanical properties of Sofia clays. Proceedings of the $6^{\text {th }}$ International Congress of Engineering Geology, 1809-1812.

Bozhinova-Haapanen, A., Uusinoka, R. 2014. X-Ray Tests on the Mineral Composition of Sofia Clay Deposits. Engineering Geology and Hydrogeology 28, 91-105.

Bruchev, I., Varbanov, R., Frangov, G., Dobrev, N., Ivanov, P., Berov, B., Diankov, H. 2006. Update landslide map of Bulgaria. National Scientific and Technical Conference "State and Control of Landslide and Erosion Processes in Bulgaria”, 23-31 (in Bulgarian).

Fellenius, W. 1927. Erdstatische Berechnungen mit Reibung und Kohäsion (Adhäsion) und unter Annahme Kreiszlunarischer Gleitflächen. Ernst \& Sohn, Berlin, 42 pp.

Frangov, G. 1990. Main regularities in the distribution of technogenic landslides in Bulgaria. Review of the Bulgarian Geological Society 51 (3), 79-85 (in Bulgarian, with English abstract). 
Frangov, G., Dobrev, N. 1991. Distribution, features and activity of the landslides in the area of Bankya. Construction 9-10, 12-17.

Iliev-Broutchev, I. (Ed.). 1994. Geological hazards in BulgariaMap in scale 1:500 000 and explanatory text. Military Topographic Service, Troyan/“Prof. Marin Drinov” Academic Press, Sofia, 143 pp. (in Bulgarian, with English abstract).

Ivanov, P. 1996. Engineering geological properties of the sediments in Sofia basin and their susceptibility to subsidence. Proceedings of the First Working Group Meeting "Expert Assessment of Land Subsidence Related to Hydrogeological and Engineering Geological Conditions in the Regions of Sofia, Skopje and Tirana”, 36-41.

Ivanov, P. 1997. Assessment of the Geological Conditions in the Sofia Kettle under Seismic Impact. Proceedings of the International Symposium on Engineering Geology and the Environment, 1265-1270.

Ivanov, P. 2001. Deformation Properties of the Neogene Sediments in Sofia kettle. Proceedings of the Final Conference "Expert Assessment of Land Subsidence Related to Hydrogeological and Engineering Geological Conditions in the Regions of Sofia, Skopje and Tirana”, 27-34.

Ivanov, P. 2002. Engineering geological conditions in the Sofia Kettle and consequences from the earthquakes. Geologica Balcanica 32 (2-4), 117-122.

Ivanov, P., Angelova, D. 1997. Geoecological assessment of the slope surfaces in the Sofia Kettle. Proceedings of the International Symposium on Engineering Geology and the Environment, 1271-1276.

Ivanov, P., Frangov, G. 2000. Engineering-geological prerequisites for the seismic-hydrodynamic phenomena in the region of Gnilyane (Sofia District) during the Krupnik Earthquake in 1904. Reports on Geodesy 4 (49), 155-162.
Ivanov, P., Frangov, G., Yaneva, M. 1998. Engineering geological characteristics of Quaternary sediments in Sofia graben. Proceedings of the $3^{\text {rd }}$ Working Group Meeting "Expert Assessment of Land Subsidence Related to Hydrogeological and Engineering Geological Conditions in the Regions of Sofia, Skopje and Tirana”, 29-32.

Ivanov, P., Frangov, G., Yaneva, M. 1998. Distribution, composition and properties of Quaternary deposits in Sofia kettle. Proceedings of the XVI Congress of the CBGA, p. 328.

Konstantinov, B., Angelov, K., Lakov, A., Stojnev, S., Konstantinov, V. 1992. Landslides activation from earthquake motions. Proceedings of the Sixth International Symposium on Landslides (ISL 1992), 1181-1186.

Krastanov, M. 2020. Assessment of destabilizing factors on a potential landslide slope in Sofia kettle - Example from the German village area, Bulgaria. Proceeding of the $1^{\text {st }}$ International Conference on Environmental Protection and Disaster Risks, 420-431.

Stoynev, S., Lakov, A. 2017. Deformation properties of the Pliocene clays from the Sofia Basin. Journal of Mining and Geological Sciences 60 (1), 128-131.

Svalova, V.B., Zaalishvili, V.B., Ganapathy, G.P., Ivanov, P.G. 2020. Engineering and technical methods for landslide risk management and reduction. Sustainable Development of Mountain Territories 12 (1), 162-170, https://doi. org/10.21177/1998-4502-2020-12-1-162-170.

Yaneva, M., Berov, B., Frangov, G. 2002. Evolution of Sofia Basin during the Neogene. Geologica Balcanica 32 (2-4), 135-138.

Yaneva, M., Donkova, Y. 2017. Quaternary deposits of the alluvial rivers in Sofia Basin. Comptes rendus de l'Académie bulgare des Sciences 70 (1), 103-110. 